\title{
Is Highly Organized Life Present on Recently Discovered Planets in Our Galaxy?
}

\author{
Wennan Long, George V. Chilingar \\ Petroleum Engineering Program, Mork Family Department, University of Southern California, Los Angeles, CA, USA \\ Email:wlong@usc.edu
}

How to cite this paper: Long, W.N. and Chilingar, G.V. (2017) Is Highly Organized Life Present on Recently Discovered Planets in Our Galaxy? Atmospheric and Climate Sciences, 7, 298-300.

http://dx.doi.org/10.4236/acs.2017.73021

Received: April 10, 2017

Accepted: July 7, 2017

Published: July 10, 2017

Copyright () 2017 by authors and Scientific Research Publishing Inc. This work is licensed under the Creative Commons Attribution International License (CC BY 4.0).

http://creativecommons.org/licenses/by/4.0/

\begin{abstract}
The question arises whether organized life (as it exists on the Earth) exists on newly-found planets or not, such as Kepler 186f, in our Galaxy. The Earth's evolution is defined by three critical factors: 1) Solar luminosity, 2) The distance between the Earth and Sun and 3) The Earth's mass and chemical compositions. All these variables were favorable for the emergence and development of highly-organized life on our Earth.
\end{abstract}

\section{Keywords}

Origin of Life, Uniqueness of the Earth, Kepler 186f, Newly-Found Planets, Earth's Evolution

\section{Introduction}

The distance of our Earth from the sun is optimal. If this distance were smaller, the surface would have been too hot and an irreversible greenhouse effect (like the one on Venus) would have occurred [1]. If the distance were greater, the Earth would have been frozen and become the "white" planet with stable ice-cover. The formation of a massive satellite Moon at the close-to-Earth orbit "pumped" the Earth with tidal energy, accelerated its tectonic development, and spun-off the Earth in the direction conducive for a more uniform climate [2].

If the Earth would not have had a massive satellite, then the tectonic activity of Earth (like Venus) would have been delayed by 2.5 to 3 billion years [2]. At the present time, under such a scenario, the conditions of the Late Archaean time (high surface temperatures and dense carbon dioxide atmosphere) would have been dominant on Earth. Consequently, instead of contemporary highly-organized life species, the Earth would have been populated only by primitive bacteria (single-cell prokaryotes). 


\section{Discussion}

If the sun were an unstable star, then the Earth would have been either unbearably hot or cold. If the sun's mass were considerably higher, then several tens or hundreds of million years after its formation, it would have exploded and turned into a neutron star or even a black hole. The sun is a quiet stationary star with a medium mass (spectral class G2), which only slightly changes its luminosity over many billions of years. This is especially important because during the last 4 billion years, the Earth's life was allowed to develop through a long evolutionary path: from primitive life to its highest forms (humans).

Considering that the Earth's evolution is closely linked to the sun and moon [3], one is surprised by the degree of the system's balance, which ensured the formation of comfortable conditions for evolution and the development of highly organized life on our Earth. Scrutinizing this system, one can observe an optimal mass of Earth, which is able to hold a moderately dense atmosphere on its surface, and also an extremely favorable chemical composition. Even insignificant deviations from the initial concentrations of $\mathrm{Fe}, \mathrm{FeO}, \mathrm{CO}_{2}, \mathrm{H}_{2} \mathrm{O}, \mathrm{N}_{2}$, etc., could have led to irreversible and catastrophic consequences for life.

If the original Earth matter contained less water, then the rate of absorption of carbon dioxide would have declined, accumulating in the Earth's atmosphere. As a result, just as during the Archaean time, an irreversible greenhouse effect could have arisen, and the Earth would have become a "hot" Venus-like planet. If the content of water were considerably higher or lower than the free iron content, then the Earth would have turned into the planet "ocean." If the content of nitrogen in our Earth were less, then in the Early Proterozoic time, the Earth would have been a "white," cold planet covered with ice and snow. Under the conditions of higher concentration of free (metallic) iron, the free oxygen would not have been able to accumulate in the contemporary (as well as in Proterozoic) atmosphere and, consequently, the kingdom of animals would not have emerged on the Earth. On the other hand, in the case of lower initial concentration of iron, at the present time (or even earlier), an intense emission of endogenic (abiogenic) oxygen should have occurred, with all the life species "burning" in such an atmosphere. In addition, the outgassing of deep-seated oxygen should have led to a strong greenhouse effect, which would have converted the Earth into a "hot" Venus-like planet. This implies that the time of existence of highly-organized and, especially, intelligent life on any of the planets of the stellar systems of the universe is relatively limited.

\section{Conclusion}

It was fortunate that our Earth has a comfortable nitrogen-oxygen atmosphere and remarkable land for life. Our "lucky" planet, Earth, represents an exceptionally rare phenomenon in the universe. Thus, it is improbable to find another planet populated with intelligent species in our galaxy (O. G. Sorokhtin, 2005, personal communication). In conclusion, the writer of this article (an Earth Scientist) believes in the divine origin of life on Earth. Thus, the question 
whether life exists on newly-found planets or not will be answered after further studies.

\section{References}

[1] Sorokhtin, O.G., Chilingar, G.V. and Khilyuk, L. (2007) Evolution of Climate on Earth: Global Warming and Global Cooling. Elsevier, Amsterdam, 450 p.

[2] Sorokhtin, O.G., Chilingar, G.V. and Sorokhtin, N.O. (2010) Theory of Earth Development (Origin, Evolution and Tragic Future). Institute Computer Studies, Izhevsk, 751p. (In Russian)

[3] Sorokhtin, O.G. and Ushakov, S.A. (2002) Evolution of Earth. Moscow Government University, Moscow, 560 p.

Submit or recommend next manuscript to SCIRP and we will provide best service for you:

Accepting pre-submission inquiries through Email, Facebook, LinkedIn, Twitter, etc. A wide selection of journals (inclusive of 9 subjects, more than 200 journals) Providing 24-hour high-quality service User-friendly online submission system Fair and swift peer-review system Efficient typesetting and proofreading procedure Display of the result of downloads and visits, as well as the number of cited articles Maximum dissemination of your research work

Submit your manuscript at: http://papersubmission.scirp.org/

Or contact acs@scirp.org 